\title{
Eksplorasi Metode Triple Exponential Smoothing Pada Peramalan Jumlah Penggunaan Air Bersih di PDAM Kota Makassar
}

\author{
Suci Lestari, Ansari Saleh Ahmar*, \& Ruliana \\ Program Studi Statistika, Fakultas Matematika dan Ilmu Pengetahuan Alam, Universitas Negeri Makassar, Indonesia
}

Keywords: Water, triple exponential smoothing, time series, and forecasting.

\begin{abstract}
:
The availability of clean water is very crucial important because almost all of human activities need water. This makes the production factor and availability of clean water are always being a priority in clean water distibution service. Thats why, the author intended to study about the forecasting about the use of clean water in PDAM, Makassar. One of the suitable method to handle this condition is Time Series method. Triple Exponential Smoothing method and also called Winter Exponential Smoothing is one of Time Series method which is suitable to handle the seasonal data like the amount of the clean water usage in Makassar. Even there, the analysis step of Triple Exponential Smoothing is Identification model, parameter estimation by trial and error, then calculation of the initial value of data smoothing, trend, and seasonal which one season long is $\mathrm{L}=12$ and the last is calculating the error value by using MAPE and RMSE. The best model is obtained from the combination of parameter $\alpha=0,1 ; \beta=0,1 ; \gamma=0,6$ which produce the smallest forecasting error by using RMSE with a value of 168,175 and MAPE value is 4,736. By using model

$F_{t+m}=\left(0,1 \frac{X_{t}}{S N_{t-1}}+(0,9)\left(S_{t-1}+T_{t-1}\right)+0,1\left(S_{t}-S_{t-1}\right)+(0,9) T_{t-1} \cdot m\right) 0,6\left(\frac{X_{t}}{S_{t}}\right)+(0,4) S N_{t-L+m}$

The result of this study is forecasting about the amount of clean water usage in PDAM, Makassar from January - December 2019 as follows : 2779,10, 2788,94, 2728,61, 2797,28, $2787,97,2752,66,2742,18,2708,50,2644,55,2521,50,2537,74,2732$, 55. From the forecasting results, it showed that the current data was approaching and not too deviating from the last year's data and it could be used as a reference of clean water productivity in PDAM, Makassar so the water productivity could suply all the societies' need.
\end{abstract}

\section{Pendahuluan}

Air merupakan salah satu kebutuhan pokok yang sangat berperan penting bagi seluruh makhluk hidup tidak terkecuali manusia. Kebutuhan akan air bersih yang dapat digunakan harus melalui tahap pengelolaan. Perusahaan Daerah Air Minum selalu ada di setiap wilayah di Indonesia khususnya kota-kota besar termasuk di kota Makassar sebagai pemenuhan sumber kehidupan.

Semakin meningkatnya pertumbuhan penduduk di setiap daerah di Indonesia maka pemenuhan kebutuhan air bersih juga akan semakin besar. Penggunaan air yang tinggi mengakibatkan kebutuhan akan permintaan ketersediaan air besih terus meningkat sedangkan persediaan air bersih sendiri setiap tahun jumlahnya terus berkurang seiring dengan banyaknya lahan hijau terbuka yang dijadikan pemukiman atau banguna. Proses untuk memperkirakan kebutuhan air yang harus diproduksi di PDAM kota Makassar sangatlah penting, dikarenakan tanpa adanya perkiraan dapat mengakibatkan kurang atau berlebihnya kebutuhan air yang disediakan oleh PDAM kota Makassar pada masa yang akan datang. Oleh karena itu, dengan mempertimbangkan segala hal yang terjadi di masa lalu maka sangat diperlukan

\footnotetext{
* Corresponding author.

E-mail address: ansarisaleh@unm.ac.id
} 
adanya suatu sistem yang dapat meramalkan jumlah kebutuhan air yang diproduksi nantinya dapat berguna untuk memudahkan persediaan kebutuhan air dimasa yang akan datang. Jika jumlah penggunaan air bersih perbulannya dapat diramalkan, maka jumlah air bersih yang harus diproduksi juga dapat ditentukan.

Peramalan adalah teknik untuk memperkirakan nilai atau data pada masa yang akan datang dengan memperhatikan data masa lalu maupun data saat, salah satunya dapat dilakukan dengan menggunakan analisis deret waktu (time series) ini ( Aswi \& Sukarna, 2006).

Data jumlah penggunaan air oleh masyarakat yang tersedia di PDAM Kota Makassar membentuk suatu kurva yang polanya memperlihatka adanya trend dan musiman. Salah satu metode time series yang digunakan untuk melakukan peramalan adalah Exponential Smoothing. Melalui Penelitian ini, diharapkan mampu memberikan gambaran hasil ramalan jumlah penggunaan air bersih oleh masyarakat di kota Makassar. Oleh karena itu, peneliti tertarik untuk mengkaji peramalan jumlah penggunaan air bersih yang harus di produksi di Kota Makassar dengan menggunakan metode Exponential Smoothing yakni Triple Exponential Smoothing atau biasa disebut dengan Winter Exponential Smoothing. Sangat penting untuk dilakukan suatu peramalan untuk memprediksi kebutuhan air di Kota Makasar agar produksi air bersih selalu mencukupi kebutuhan masyarakat di Kota Makassar.

Berdasarkan karakteristik data yang mengandung musiman, maka peramalan dilakukan dengan menggunakan metode Triple Exponential Smoothing dimana penelitian ini akan memperoleh model yang tepat untuk hasil ramalan jumlah penggunaan air bersih oleh masyarakat kota Makassar sehingga dapat ditentukan suatu jumlah air bersih yang harus di produksi oleh PDAM kota Makassar.

\section{Tinjauan Pustaka}

\subsection{Peramalan}

Peramalan berasal dari kata ramalan yaitu suatu kondisi untuk memperkirakan yang akan terjadi di masa depan (Putri, 2012). Apabila metode peramalan ini diterapkan dalam bagian proses perencanaan produksi maka pihak perusahaan akan lebih terbantu dalam penjadwalan produksi, karena resiko kesalahan yang disebabkan oleh kesalahan perencanaan dapat ditekan seminimal mungkin (Fiati, 2010). Ramalan tersebut bisa didasarkan atas bermacammacam cara, salah satunya yaitu dengan menggunakan metode Triple Exponential Smoothing. Peramalan yang dilakukan diharapkan mampu memperkecil pengaruh ketidakpastian terhadap suatu masalah. Hal ini bertujuan untuk mendapatkan peramalan yang bisa meminimumkan kesalahan meramal dengan menggunakan Root Mean Square Error (RMSE), dan Mean Absolute Percetage Error (MAPE).

\subsection{Pemulusan Eksponential (Exponential Smoothing)}

Peramalan Exponential Smoothing merupakan salah satu metode dalam time series yang menggunakan pembobotan data masa lalu secara exponential. Dalam hal ini, metode Exponential Smoothing terbagi atas tiga yaitu Single Exponential Smoothing yang digunakan untuk pemulusan data yang stasioner, tidak memiliki trend dan variasi musiman sehingga hanya menggunakan satu parameter yaitu alpha $(\alpha)$, Double Exponential Smoothing yang digunakan dalam pemulusan data yang memuat trend namun tidak memiliki variasi musiman, memiliki dua parameter pemulusan yaitu alpha $(\alpha)$ dan beta $(\beta)$, dan Triple Exponential Smoothing merupakan pemulusan exponential smoothing yang bertujuan untuk melakukan pemulusan pada data yang memuat trend, dan variasi musiman dengan menggunakan tiga parameter pemulusan yakni alpha $(\alpha)$, beta $(\beta)$, dan gamma $(\gamma)$. Beberapa keuntungan dari jumlah penggunaan metode Exponential Smoothing adalah banyak mengurangi masalah penyimpanan data, sehingga tidak perlu lagi menyimpan semua data historis atau sebagian; hanya pengamatan terakhir, ramalan terakhir, dan suatu nilai konstanta yang harus disimpan. (Makridakis dkk, 1999). Hal ini disebabkan karena metode ini memiliki keunggulan dibandingkan metode-metode lainnya, yaitu metode penghalusan eksponensial bersifat sederhana, intuitif dan mudah dipahami. Artinya, walaupun sederhana namun sangat berguna bagi peramalan jangka pendek (shortterm forecasting) dari data time series yang panjang (Suwandi, 2015). 


\subsection{Metode Pemulusan Triple Exponential Smoothing/Winter Exponential Smoothing}

Metode Triple Exponential Smoothing merupakan metode dalam time series yang didasarkan atas tiga persamaan pemulusan yaitu satu untuk stasioner, trend, dan musiman dengan menggunakan tiga parameter pemulusan yakni $\alpha$, $\beta, \gamma$ yang masing-masing bernilai antara $0-1$. Adapun nilai peramalan dapat dicari dengan persamaan menurut (Bossarito, 2018):

Pemulusan Musiman :

$$
S N_{t}=\gamma\left(\frac{X_{t}}{S_{t}}\right)+(1-\gamma) S N_{t-L}
$$

Pemulusan data :

$$
S_{t}=\alpha \frac{X_{t}}{S N_{t-1}}+(1-\alpha)\left(S_{t-1}+T_{t-1}\right)
$$

Pemulusan trend:

$$
T_{t}=\beta\left(S_{t}-S_{t-1}\right)+(1-\beta) T_{t-1}
$$

Peramalan :

$$
\begin{aligned}
& F_{t+m}=\left(S_{t}+T_{t} m\right) S N_{t-L+m} \\
& F_{t+m}=\left(\alpha \frac{X_{t}}{S N_{t-1}}+(1-\alpha)\left(S_{t-1}+T_{t-1}\right)+\beta\left(S_{t}-S_{t-1}\right)+(1-\beta) T_{t-1} m\right) \gamma\left(\frac{X_{t}}{S_{t}}\right) \\
& F_{t+m}=+(1-\gamma) S N_{t-1}
\end{aligned}
$$

Dengan :

$$
\begin{array}{ll}
X_{t} & =\text { data aktual pada waktu ke- } \mathrm{t}, \\
S_{t} & =\text { nilai pemulusan data, } \\
S_{t-1} & =\text { nilai pemulusan data sebelumnya, } \\
T_{t} & =\text { pemulusan trend } \\
T_{t-1} & =\text { pemulusan trend periode sebelumnya, } \\
S N_{t} & =\text { pemulusan musiman, } \\
S N_{t-1} & =\text { pemulusan musiman periode sebelumnya, } \\
\alpha & =\text { parameter exponential untuk pemulusan } \\
& \quad \text { data dengan nilai antara } 0 \text { dan } 1, \\
\beta & =\text { parameter exponential untuk pemulusan } \\
& \quad \text { trend dengan nilai antara } 0 \text { dan } 1 \\
\gamma & =\text { parameter exponential untuk pemulusan } \\
& \text { musiman dengan nilai antara } 0 \text { dan } 1 \\
F_{t+m} & =\text { nilai peramalan, } \\
m & =\text { periode waktu yang akan diramalkan. } \\
\mathrm{L} & =\text { panjang musiman }
\end{array}
$$

\subsection{PDAM (Perusahaan Daerah Air Minum)}

Menurut (Kurniawati, 2009) Perusahaan daerah merupakan salah satu pelaku ekonomi di suatu daerah, selain perusahaan milik negara, perusahaan swasta dan koperasi. Tujuan pemerintah mendirikan perusahaan daerah yaitu untuk menjadi penyokong dalam pembangunan daerah. PDAM adalah satu dari beberapa Badan Usaha Milik Daerah (BUMD), yang mengelola kebutuhan air minum. Aktivitas PDAM antara lain mengumpulkan air bahan baku atau air yang kurang bersih, mengolah menjadi air bersih dan sampai mendistribusikan air ke pelanggan. Di masa yang akan datang PDAM mempunyai prospek ekonomi yang sangat cerah, ini dibuktikan dengan melihat pertumbuhan jumlah pelanggan yang terus meningkat. Untuk mencukupi kebutuhan konsumennya perusahaan air minum selalu meningkatkan pelayanan baik dari segi kualitas maupun produktivitas. Sehingga dalam hal ini sangat dibutuhkan sistem untuk memprediksi pemakaian air yang berdasarkan dari pemakaian sehari-hari dalam setiap bulannya sebagai acuan untuk merencakan produksi dan pendistribusian air di bulan dan tahun berikutnya. 


\subsection{Ketetapan Peramalan}

Ketetapan ramalan adalah suatu hal yang sangat penting untuk peramalan, yaitu bagaimana mengukur kesesuaian anatara data yang sudah ada dengan data peramalan. Ada beberapa metode yang biasa digunakan dalam menghitung kesalahan hasil peramalan (forecast error).

\subsubsection{Root Mean Square Error (RMSE)}

RMSE adalah nilai rata-rata dari jumlah kuadrat kesalahan yang dihasilkan oleh suatu model peramalan. Nilai dari Root Mean Square Error (RMSE) menunjukkan perbedaan antara hasil peramalan dengan hasil yang akan diramalkan. Metode RMSE menghitung keakuratan hasil peramalan menggunakan data history. . RMSE dapat dicari dengan menggunakan rumus berikut :

$$
R M S E=\sqrt{\frac{\sum\left(X_{t}-F_{t}\right)^{2}}{n}}
$$

Dengan :

$X t=$ nilai aktual pada data ke $\mathrm{t}$,

$F_{t}=$ Nilai peramalan pada data ke $\mathrm{t}$,

$n=$ jumlah periode data.

\subsubsection{Mean Absolute Persentage Error}

MAPE merupakan pengukuran kesalahan yang menghitung ukuran presentase penyimpangan antara data aktual dengan data peramalan. Menurut (Chang P.C., 2007) Nilai MAPE dapat dicari dengan menggunakan rumus pada persamaan:

$$
M A P E=\frac{\sum_{t=1}^{n}\left|\frac{X_{t}-F_{t}}{X_{t}}\right|}{n} x 100 \%
$$

\section{Dengan:}

$X t=$ nilai aktual pada data $t$,

$F t=$ nilai peramalan pada data $t$,

$n=$ jumlah periode data.

\section{Metode Penelitian}

Adapun prosedur dalam penelitian ini:

1. Mengumpulkan dan Clearing Data

Mengumpulkan, Mengimput data jumlah penggunaan air di PDAM kota Makassar dari Januari 2015-Desember 2018.

2. Memplot data jumlah penggunaan Air di PDAM Kota Makassar agar membantu dalam mengamati pola data.

3. Penentuan Nilai Parameter

Untuk mendapatkan nilai ramalan dengan menggunakan metode triple exponential smoothing, diperlukan nilai alpha $(\alpha)$, betta $(\beta)$, dan gamma $(\gamma)$ yang di optimalkan berdasarkan MAPE yang paling minimum. Dalam metode exponential smoothing, nilai $\alpha$ bisa ditentukan secara bebas, artinya tidak ada suatu cara yang pasti untuk mendapatkan nilai $\alpha$ yang optimal. Metode yang digunakan untuk mengetimasi parameter model ialah dengan cara simulasi (trial and error), yakni mensimulasi kisaran nilai $\alpha, \beta$, dan $\gamma$ pada interval ( 0 dan 1). Nilai alpha $(\alpha)$, betta $(\beta)$, dan gamma $(\gamma)$ yang optimal tersebut juga dapat ditentukan langsung oleh program aplikasi yang telah dirancang. Selanjutkan setelah didapatkan nilai alpha $(\alpha)$, betta $(\beta)$, dan gamma $(\gamma)$ yang optimal maka akan dilakukan perhitungan nilai MAPE sebagai alat ukur keakuratan peramalannya. Setelah mendapat nilai alpha $(\alpha)$, betta $(\beta)$, dan gamma $(\gamma)$ yang optimal, maka dilakukan perhitungan dan peramalan untuk tiap jenis datanya. 
4. Penentuan Nilai Awal

Nilai awal adalah nilai yang digunakan untuk menduga nilai awal. Jika data deret berkala tidak ada untuk memenuhi koefisien tersebut, maka untuk menentukan nilai tersebut dapat dilakukan dengan menghitung nilai prediksinya dengan menganalogikan dengan beberapa metode. Pada penelitian ini, panjang satu musim $\mathrm{s}=12$ dan perhitungan nilai awal dari pemulusan data, trend, dan musiman sebagai berikut.

a) Nilai awal pemulusan eksponensial. Nilai awal untuk pemulusan total yaitu dengan menghitung rata-rata pada data di tahun pertama. Adapun penentuan nilai awal pemulusan periode ke-12 adalah $\mathrm{L}_{12}$ sebagai berikut:

$$
\begin{aligned}
& S_{12}=\frac{1}{12}\left(X_{1}, X_{2}, X_{3}, \ldots, X_{12}\right) \\
& S_{12}=\frac{1}{L} \sum_{i=1}^{12} X_{t}
\end{aligned}
$$

Dengan :

$\mathrm{S}_{12}=$ Nilai Awal pemulusan eksponensial

$\mathrm{X}=$ data ke-t

$\mathrm{L}=$ panjang periode musiman.

b) Nilai awal untuk pemulusan trend

$$
\begin{aligned}
& T_{12}=\frac{1}{12}\left(\frac{X_{12+1}-X_{1}}{12}+\frac{X_{12+2}-X_{2}}{12}+\ldots+\frac{X_{12+12}-X_{12}}{12}\right. \\
& T_{12}=\frac{1}{12}\left(\frac{X_{13}-X_{1}}{12}+\frac{X_{14}-X_{2}}{12}+\ldots+\frac{X_{24}-X_{12}}{12}\right. \\
& T_{12}=\frac{1}{L}\left(\frac{X_{L}-X_{1}}{L}+\frac{X_{L+2}-X_{2}}{L}+\ldots+\frac{X_{L}-X_{12}}{L}\right. \\
& \mathrm{T}_{12}=\text { nilai awal untuk faktor } \text { trend } \\
& \mathrm{X}=\text { data ke } \mathrm{t} \\
& \mathrm{L}=\text { panjang musiman }
\end{aligned}
$$

c) nilai awal untuk pemulusan musiman:

$$
\begin{aligned}
& S N_{1}=\frac{X_{1}}{L s} \\
& S N_{2}=\frac{x_{2}}{L s} \\
& S N_{3}=\frac{x_{3}}{L s} \\
& \cdot \\
& S N_{t}=\frac{X N_{t}}{L s}
\end{aligned}
$$

Dengan :

$\mathrm{SN}_{\mathrm{t}}=$ Nilai awal untuk faktor musiman ke-n

$\mathrm{XN}=$ data ke- $\mathrm{t}$

$$
\mathrm{t}=\text { periode musiman, }(k=1,2, \ldots, L)
$$

5. Pemilihan model terbaik (RSME dan MAPE) dilihat dari kesalahan ramalan yang terkecil dengan memperhitungkan nilai perhitungan RMSE dan MAPE. Semakin kecil kesalahan yang diperoleh maka peramalan semakin baik.

6. Perhitungan metode Triple Exponential Smoothing

Setelah mendapatkan nilai awal maka dilanjutkan dengang perhitungan Triple Exponential Smoothing yang memerlukan nilai awal dari pemulusan data, trend, dan musiman, perhitungan berdasar pada persamaan (2.3.1), (2.3.2), dan (2.3.3).

7. Melakukan peramalan periode selanjutnya dengan rumus:

$$
F_{t+m}=\left(S_{t}+T_{t} m\right) S N_{t-L+m}
$$




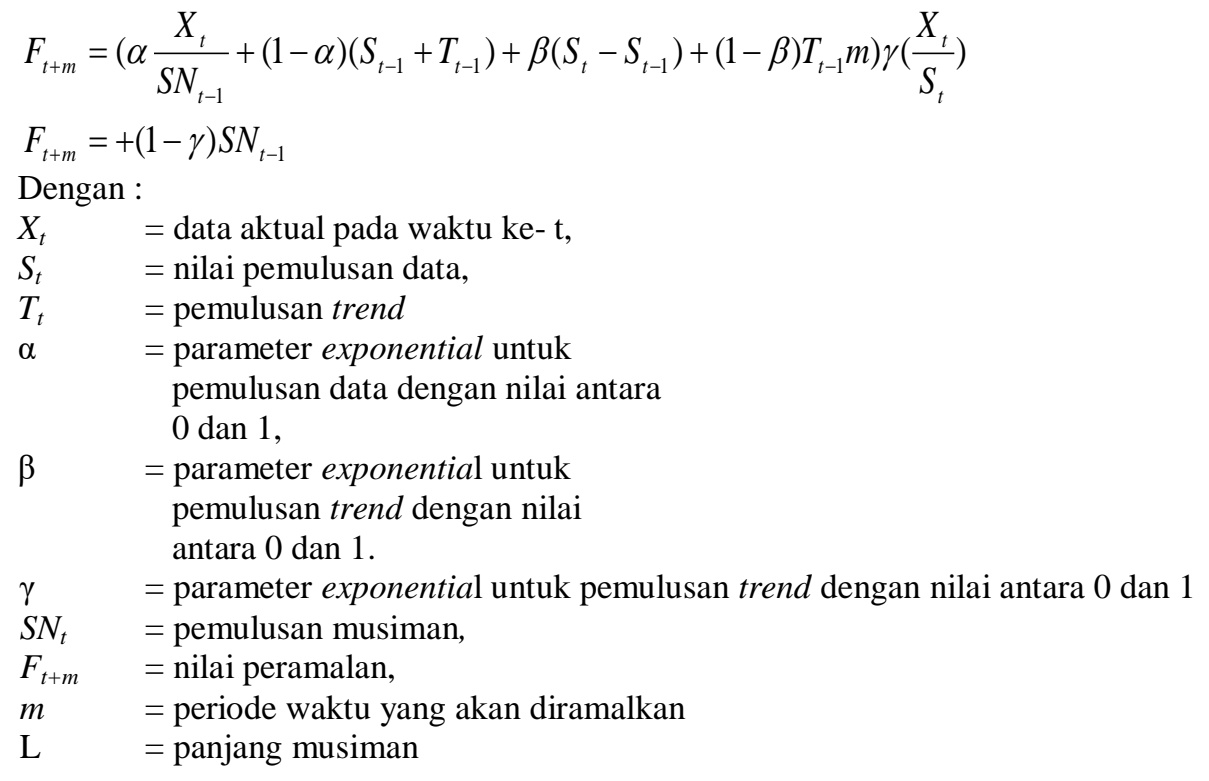

\section{Hasil dan Pembahasan}

\subsection{Hasil Penelitian}

\subsubsection{Eksplorasi Parameter Metode Triple Eksponential Smoothing}

Sudah menjadi ketetapan bahwa dalam penentuan suatu parameter pemulusan secara simulasi (trial and error), nilai $\alpha, \beta, \gamma$ berkisar pada interval 0 sampai dengan 1 artinya bahwa 0 dan 1 tidak dapat digunakan pada nilai paramater $\alpha$, $\beta, \gamma$. Sehingga dilakukan ekplorasi parameter yang memperlihatkan bagaimana ketika suatu parameter pada metode triple exponential smoothing bernilai 0 dan 1 . Dengan adanya eksplorasi Parameter maka dapat dilihat apakah ketika nilai $\alpha, \beta, \gamma$ bernilai 0 dan 1 metode triple exponential smoothing dapat menjadi metode double exponential smoothing atau single exponential smoothing. Dilakukan kombinasi pada parameter $\alpha, \beta, \gamma$ bernilai 0 dan 1 sebanyak 8 model kombinasi parameter.

Dengan menggunakan persamaan (2.1), (2.2), (2.3) dan (2.5) maka dilakukan eksplorasi parameter dengan nilai $\alpha, \beta, \gamma$ sebagai berikut:

a) Untuk $\alpha=0, \beta=0, \gamma=0$ diperoleh:

$$
\begin{aligned}
& S_{t}=0 \frac{X_{t}}{S N_{t-1}}+(1-0)\left(S_{t-1}+T_{t-1}\right) \\
& S_{t}=\left(S_{t-1}+T_{t-1}\right) \\
& T_{t}=0\left(S_{t}-S_{t-1}\right)+(1-0) T_{t-1} \\
& T_{t}=T_{t-1} \\
& S N_{t}=0\left(\frac{X_{t}}{S_{t}}\right)+(1-0) S N_{t-L} \\
& S N_{t}=S N_{t-L}
\end{aligned}
$$

Sehingga persamaan peramalannya adalah:

$$
\begin{aligned}
F_{t+m} & =\left(S_{t}+T_{t} m\right) S N_{t-L+m} \\
F_{t+m} & =\left(S_{t-1}+T_{t-1}+T_{t-1} m\right) S N_{t-L+m}
\end{aligned}
$$

b) Untuk $\alpha=0, \beta=0, \gamma=1$ diperoleh: 


$$
\begin{aligned}
& S_{t}=0 \frac{X_{t}}{S N_{t-1}}+(1-0)\left(S_{t-1}+T_{t-1}\right) \\
& S_{t}=\left(S_{t-1}+T_{t-1}\right) \\
& T_{t}=0\left(S_{t}-S_{t-1}\right)+(1-0) T_{t-1} \\
& T_{t}=T_{t-1} \\
& S N_{t}=1\left(\frac{X_{t}}{S_{t}}\right)+(1-1) S N_{t-L} \\
& S N_{t}=\frac{X_{t}}{S_{t}}
\end{aligned}
$$

Sehingga persamaan peramalannya adalah:

$$
\begin{aligned}
& F_{t+m}=\left(S_{t}+T_{t} m\right) S N_{t-L+m} \\
& F_{t+m}=\left(S_{t-1}+T_{t-1}+T_{t-1} m\right)\left(\frac{X_{t}}{S_{t}}\right)
\end{aligned}
$$

c) Untuk $\alpha=0, \beta=1, \gamma=0$ diperoleh:

$$
\begin{aligned}
& S_{t}=0 \frac{X_{t}}{S N_{t-1}}+(1-0)\left(S_{t-1}+T_{t-1}\right) \\
& S_{t}=\left(S_{t-1}+T_{t-1}\right) \\
& T_{t}=1\left(S_{t}-S_{t-1}\right)+(1-1) T_{t-1} \\
& T_{t}=S_{t}-S_{t-1} \\
& S N_{t}=0\left(\frac{X_{t}}{S_{t}}\right)+(1-0) S N_{t-L} \\
& S N_{t}=S N_{t-L}
\end{aligned}
$$

Sehingga persamaan peramalannya adalah:

$$
\begin{aligned}
& F_{t+m}=\left(S_{t}+T_{t} m\right) S N_{t-L+m} \\
& F_{t+m}=\left(S_{t-1}+T_{t-1}+S_{t}-S_{t-1}\right) S N_{t-L+m} \\
& F_{t+m}=\left(T_{t-1}+S_{t}\right) S N_{t-L+m}
\end{aligned}
$$

d) Untuk $\alpha=1, \beta=0, \gamma=0$ diperoleh:

$$
\begin{aligned}
& S_{t}=1 \frac{X_{t}}{S N_{t-1}}+(1-1)\left(S_{t-1}+T_{t-1}\right) \\
& S_{t}=\frac{X_{t}}{S N_{t-1}} \\
& T_{t}=0\left(S_{t}-S_{t-1}\right)+(1-0) T_{t-1} \\
& T_{t}=T_{t-1} \\
& S N_{t}=0\left(\frac{X_{t}}{S_{t}}\right)+(1-0) S N_{t-L} \\
& S N_{t}=S N_{t-L}
\end{aligned}
$$

Sehingga persamaan peramalannya adalah:

$$
\begin{aligned}
& F_{t+m}=\left(S_{t}+T_{t} m\right) S N_{t-L+m} \\
& F_{t+m}=\left(\frac{X_{t}}{S N_{t-1}}+T_{t-1} m\right) S N_{t-L+m}
\end{aligned}
$$

e) Untuk $\alpha=1, \beta=0, \gamma=1$ diperoleh: 


$$
\begin{aligned}
& S_{t}=1 \frac{X_{t}}{S N_{t-1}}+(1-1)\left(S_{t-1}+T_{t-1}\right) \\
& S_{t}=\frac{X_{t}}{S N_{t-1}} \\
& T_{t}=0\left(S_{t}-S_{t-1}\right)+(1-0) T_{t-1} \\
& T_{t}=T_{t-1} \\
& S N_{t}=1\left(\frac{X_{t}}{S_{t}}\right)+(1-1) S N_{t-L} \\
& S N_{t}=\frac{X_{t}}{S_{t}}
\end{aligned}
$$

Sehingga persamaan peramalannya adalah:

$$
\begin{aligned}
& F_{t+m}=\left(S_{t}+T_{t} m\right) S N_{t-L+m} \\
& F_{t+m}=\left(\frac{X_{t}}{S N_{t-1}}+T_{t-1} m\right) \frac{X_{t}}{S_{t}}
\end{aligned}
$$

f) Untuk $\alpha=0, \beta=1, \gamma=1$ diperoleh:

$$
\begin{aligned}
& S_{t}=0 \frac{X_{t}}{S N_{t-1}}+(1-0)\left(S_{t-1}+T_{t-1}\right) \\
& S_{t}=\left(S_{t-1}+T_{t-1}\right) \\
& T_{t}=1\left(S_{t}-S_{t-1}\right)+(1-1) T_{t-1} \\
& T_{t}=S_{t}-S_{t-1} \\
& S N_{t}=1\left(\frac{X_{t}}{S_{t}}\right)+(1-1) S N_{t-L} \\
& S N_{t}=\frac{X_{t}}{S_{t}}
\end{aligned}
$$

Sehingga persamaan peramalannya adalah:

$$
\begin{aligned}
& F_{t+m}=\left(S_{t}+T_{t} \cdot m\right) S N_{t-L+m} \\
& F_{t+m}=\left(S_{t-1}+T_{t-1}+S_{t}-S_{t-1} \cdot m\right) \frac{X_{t}}{S_{t}} \\
& F_{t+m}=\left(T_{t-1}+S_{t} \cdot m\right) \frac{X_{t}}{S_{t}}
\end{aligned}
$$

g) Untuk $\alpha=1, \beta=1, \gamma=0$ diperoleh:

$$
\begin{aligned}
& S_{t}=1 \frac{X_{t}}{S N_{t-1}}+(1-1)\left(S_{t-1}+T_{t-1}\right) \\
& S_{t}=\frac{X_{t}}{S N_{t-1}} \\
& T_{t}=1\left(S_{t}-S_{t-1}\right)+(1-1) T_{t-1} \\
& T_{t}=S_{t}-S_{t-1} \\
& S N_{t}=0\left(\frac{X_{t}}{S_{t}}\right)+(1-0) S N_{t-L} \\
& S N_{t}=S N_{t-L}
\end{aligned}
$$

Sehingga persamaan peramalannya adalah: 


$$
\begin{aligned}
& F_{t+m}=\left(S_{t}+T_{t} m\right) S N_{t-L+m} \\
& F_{t+m}=\left(\frac{X_{t}}{S N_{t-1}}+S_{t}-S_{t-1} m\right) S N_{t-L+m}
\end{aligned}
$$

h) Untuk $\alpha=1, \beta=1, \gamma=1$ diperoleh:

$$
\begin{aligned}
& S_{t}=1 \frac{X_{t}}{S N_{t-1}}+(1-1)\left(S_{t-1}+T_{t-1}\right) \\
& S_{t}=\frac{X_{t}}{S N_{t-1}} \\
& T_{t}=1\left(S_{t}-S_{t-1}\right)+(1-1) T_{t-1} \\
& T_{t}=S_{t}-S_{t-1} \\
& S N_{t}=1\left(\frac{X_{t}}{S_{t}}\right)+(1-1) S N_{t-L} \\
& S N_{t}=\frac{X_{t}}{S_{t}}
\end{aligned}
$$

Sehingga persamaan peramalannya adalah:

$$
\begin{aligned}
& F_{t+m}=\left(S_{t}+T_{t} m\right) S N_{t-L+m} \\
& F_{t+m}=\left(\frac{X_{t}}{S N_{t-1}}+S_{t}-S_{t-1} \cdot m\right)\left(\frac{X_{t}}{S_{t}}\right)
\end{aligned}
$$

dengan :

$\mathrm{X}_{\mathrm{t}} \quad=$ data aktual pada waktu ke- $\mathrm{t}$,

$\mathrm{S}_{\mathrm{t}}=$ nilai pemulusan data,

$\mathrm{S}_{\mathrm{t}-1} \quad=$ nilai pemulusan data sebelumnya

$\mathrm{T}_{\mathrm{t}} \quad=$ pemulusan trend

$\mathrm{T}_{\mathrm{t}-1} \quad=$ nilai pemulusan data sebelumnya

$\mathrm{SN}_{\mathrm{t}}=$ nilai pemulusan musiman,

$\mathrm{SN}_{\mathrm{t}-1}=$ nilai pemulusan musiman periode sebelumnya

$\alpha=$ parameter exponential untuk pemulusan data

$\beta \quad=$ parameter exponential untuk pemulusan trend

$\gamma=$ parameter exponential untuk pemulusan musiman

$F_{t+m}=$ nilai peramalan,

$m$ = periode waktu yang akan diramalkan.

$L \quad=$ panjang musiman (yaitu, jumlah bulan atau kwartal dalam setahun)

Dari hasil eksplorasi parameter tersebut dapat disimpulkan bahwa ketika nilai $\alpha, \beta, \gamma$ bernilai 0 dan 1 , tidak sama dengan single exponential smoothing dan double exponential smoothing, tidak sama dengan data karena tidak mengandung trend dan musiman.

\subsubsection{Deskripsi Data Jumlah Penggunaan Air Bersih di PDAM Kota Makassar}

Data yang dikumpulkan pada penelitian ini adalah data jumlah penggunaan air bersih di kota Makassar pada periode Januari 2015 - Desember 2018.

Dari Tabel 1 diketahui bahwa penggunaan air yang cukup tinggi berada di bulan Maret 2016 yaitu sebesar 3077,74 liter per detik. Sedangkan penggunaan air yang cukup rendah yaitu pada bulan oktober 2018 sebesar 2509,07 liter per detik, selanjutnya rata-rata penggunaan air selama 4 tahun dimulai januari 2014 sampai dengan desember 2018 sebesar 2859,729 liter per detik.

Adapun hasil output untuk plot data jumlah penggunaan air bersih di PDAM kota Makassar dari tahun 2015-2018 yang diselesaikan dengan Microsoft excel dapat dilihat pada Gambar 1. 
Tabel 1 Data Jumlah Jumlah Penggunaan Air Bersih di PDAM Kota Makassar dalam Satuan Liter Per Detik.

\begin{tabular}{rrrrr}
\hline \multirow{5}{*}{ Bulan } & \multicolumn{4}{c}{ Tahun } \\
\cline { 2 - 5 } & $\mathbf{2 0 1 5}$ & $\mathbf{2 0 1 6}$ & $\mathbf{2 0 1 7}$ & $\mathbf{2 0 1 8}$ \\
\hline Januari & 2880,19 & 3012,75 & 2857,91 & 2883,17 \\
Februari & 2879,31 & 3008,04 & 2883,10 & 2893,90 \\
Maret & 2881,74 & 3077,74 & 2813,14 & 2799,64 \\
April & 2915,29 & 3057,82 & 2912,78 & 2872,10 \\
Mei & 2907,84 & 3001,90 & 3042,04 & 2802,87 \\
Juni & 2930,58 & 2875,52 & 2899,29 & 2826,26 \\
Juli & 2925,49 & 2817,10 & 2902,93 & 2830,96 \\
Agustus & 2921,88 & 2827,58 & 2926,03 & 2811,14 \\
September & 2744,00 & 2669,65 & 2749,84 & 2778,44 \\
Oktober & 2545,63 & 2849,03 & 2829,45 & 2509,07 \\
November & 2603,76 & 2845,06 & 2841,62 & 2527,81 \\
Desember & 2750,71 & 2887,44 & 2839,65 & 2857,15 \\
Jumlah & $\mathbf{3 3 8 8 6 , 4 2}$ & $\mathbf{3 4 9 2 9 , 6 3}$ & $\mathbf{3 4 4 9 7 , 7 8}$ & $\mathbf{3 3 3 9 2 , 5 1}$ \\
Rata-rata & $\mathbf{2 8 2 3 , 8 7}$ & $\mathbf{2 9 1 0 , 8 0}$ & $\mathbf{2 8 7 4 , 8 2}$ & $\mathbf{2 7 8 2 , 7 1}$ \\
\hline
\end{tabular}

Sumber : Perusahaan Daerah Air Minum (PDAM) Kota Makassar, bagian produksi dan Instalasi.

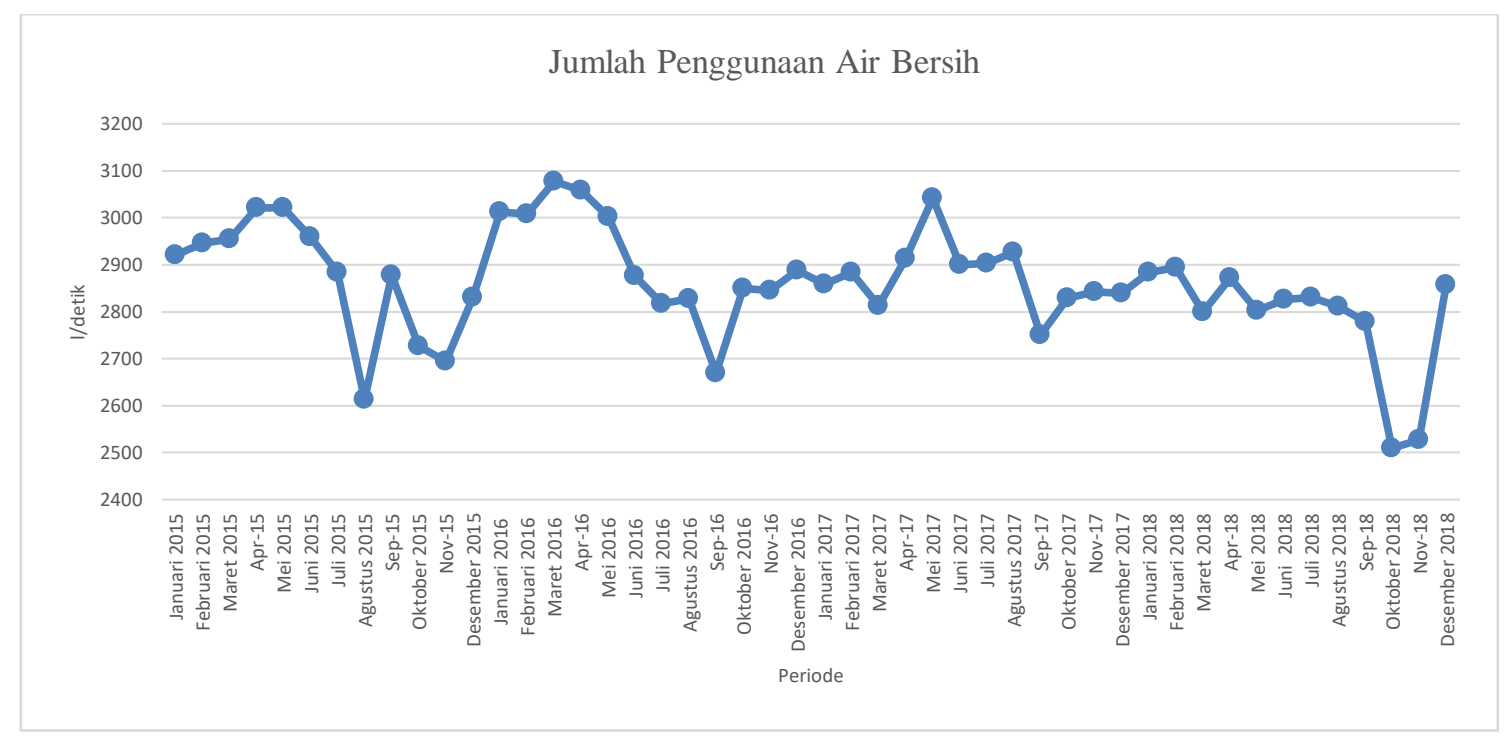

Gambar 1. Plot Data Jumlah penggunaan Air

Pada Gambar 1, sumbu horizontal (mendatar) mewakili periode sedangkan sumbu vertikal mewakili jumlah penggunaan air bersih. Adanya trend yang cenderung turun dan indikasi musiman pada waktu-waktu tertentu seperti terlihat pada Gambar 4.2, maka metode peramalan yang diterapkan adalah Triple Exponential Smoothing atau biasa disebut dengan Winter Exponential Smoothing.

Selanjutnya dilakukan juga plot dekomposisi data Jumlah Penggunaan Air Bersih di PDAM Kota Makassar. Dekomposisi digunakan untuk membagi data time series menjadi beberapa pola dan mengidentifikasi masing-masing komponen secara terpisah agar dapat membantu meramalkan data yang menunjukkan adanya pola trend dan pengaruh musiman. Perubahan suatu data biasanya memiliki pola yang agak kompleks, misalnya ada unsur kenaikan, berfluktuasi dan tidak teratur. Data dengan karasteristik tersebut akan sulit dimodelkan secara sekaligus sehingga harus diadakan pemecahan kedalam 4 komponen pola perubahan yaitu trend, musiman, fluktuasi Siklik(stasioner) dan random. 


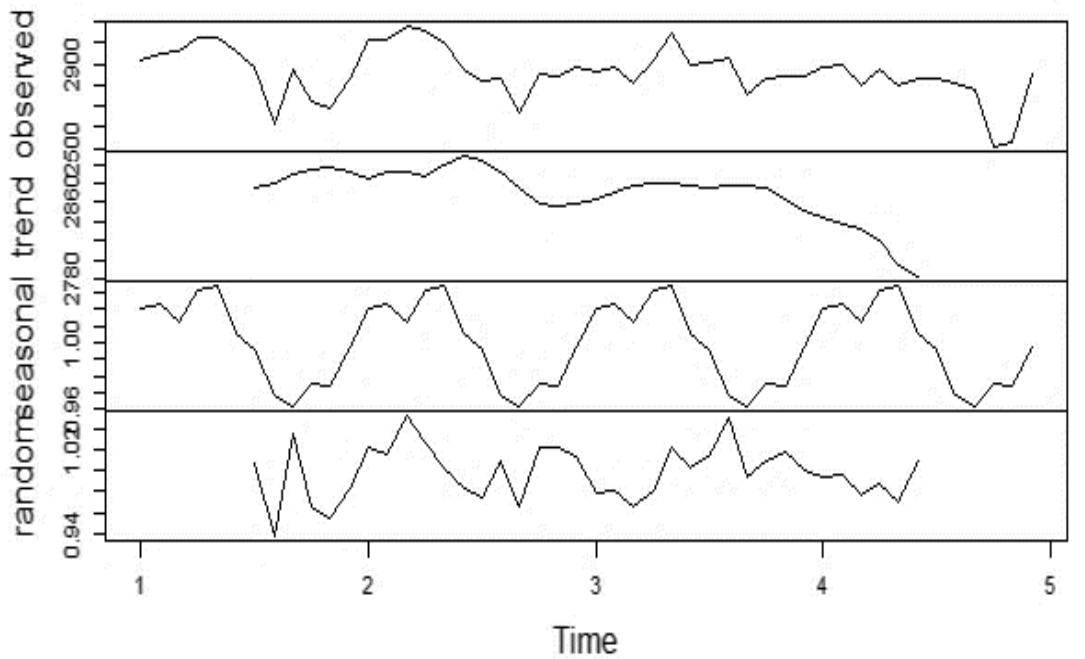

Gambar 2. Plot Dekomposisi Data Jumlah penggunaan Air

Gambar 4.3. membagi menjadi 4 komponen yaitu komponen random, seasonal, trend, dan observed dan terlihat jelas bahwa pada data Jumlah Penggunaan Air Bersih di PDAM kota Makassar memiliki pola trend yang cenderung turun dan indikasi musiman pada waktu tertentu.

\subsubsection{Penentuan Nilai Awal}

Peramalan Triple exponential smoothing memerlukan nilai awal dari pemulusan data, trend, dan musiman. Berikut ini adalah perhitungan nilai awal dari pemulusan data, trend, dan musiman dengan panjang satu musim $\mathrm{L}=12$. Penetuaan panjang satu musim dapat dengan jumlah bulan atau kwartal dalam setahun sehingga pada penelitian ini ditentukan panjang satu musim sebanyak $\mathrm{L}=12$ karena pada data penggunaan air bersih di PDAM kota Makassar menunjukkan jumlah bulan dalam setahun.

a) Nilai awal suatu pemulusan data dari periode ke-12 dengan notasi $\mathrm{S}_{12}$. Perhitungan untuk nilai awal pemulusan data periode ke 12 adalah

$S_{12}=\frac{1}{12}\left(X_{1}+X_{2}+X_{3}+\ldots+X_{t}\right)$

$S_{12}=\frac{1}{12} \sum_{i=1}^{12} X_{t}$

Dengan $\mathrm{X}_{\mathrm{t}}$ data penggunaan air pada periode ke $t$ dengan $t 1,2,3, \ldots, 12$

$S_{12}=\frac{1}{12}(2920,49+2945,87+2954,95+\ldots+2830,89)$ Jadi nilai awal pemulusan data pada periode ke- 12 yaitu $S_{12}=$

$S_{12}=2870,589$

2870,589 1/detik.

b) Nilai awal pemulusan trend periode ke-12 yaitu $b_{12}$.

$T_{12}=\frac{1}{12}\left(\frac{X_{12+1}-X_{1}}{12}+\frac{X_{12+2}-X_{2}}{12}+\ldots+\frac{X_{12+12}-X_{12}}{12}\right.$

$T_{12}=\frac{1}{12}\left(\frac{X_{13}-X_{1}}{12}+\frac{X_{14}-X_{2}}{12}+\ldots+\frac{X_{24}-X_{12}}{12}\right.$

$T_{12}=3,351111$

Jadi nilai awal trend periode ke 12 yaitu 3, 351111.

c) Nilai awal pemulusan musiman 


$$
\begin{aligned}
& S N_{1}=\frac{X_{1}}{L s} \\
& S N_{2}=\frac{X_{2}}{L s} \\
& S N_{3}=\frac{X_{3}}{L s} \\
& \cdot \\
& S N_{t}=\frac{X N_{t}}{L s}
\end{aligned}
$$

Diketahui nilai dari $\mathrm{S}_{12}$ adalah 2870,589 dan dari persamaan diperoleh nilai awal pemulusan musiman untuk periode ke-1 adalah sebagai berikut.

$$
\begin{aligned}
& S N_{1}=\frac{2920,49}{2870,589} \\
& S N_{1}=1,017383
\end{aligned}
$$

Dengan cara yang sama selanjutnya dilakukan untuk perhitungan $\mathrm{SN}_{2}, \mathrm{SN}_{3}, \ldots, \mathrm{SN}_{12}$. Sehingga hasil perhitungan nilai awal pemulusan musiman dapat dilihat di Tabel 2.

Tabel 2. Nilai Awal Pemulusan Musiman

\begin{tabular}{cccc}
\hline No. & Bulan & Data & SN $_{\mathbf{t}}$ \\
\hline 1 & Januari 2015 & 2920,49 & 1,017383 \\
2 & Februari 2015 & 2945,87 & 1,026225 \\
3 & Maret 2015 & 2954,95 & 1,029388 \\
4 & April 2015 & 3020,49 & 1,052220 \\
5 & Mei 2015 & 3021,02 & 1,052404 \\
6 & Juni 2015 & 2958,39 & 1,030586 \\
7 & Juli 2015 & 2883,69 & 1,004564 \\
8 & Agustus 2015 & 2613,48 & 0,910433 \\
9 & September 2015 & 2877,21 & 1,002306 \\
10 & Oktober 2015 & 2726,41 & 0,949774 \\
11 & September 2015 & 2694,18 & 0,938546 \\
12 & Desember 2015 & 2830,89 & 0,986170
\end{tabular}

\subsubsection{Perhitungan Nilai Pemulusan}

Setelah didapatkan nilai awal pemulusan data, trend, dan musiman, maka dilakukan perhitungan nilai pemulusan data, trend, dan musiman untuk periode ke- 13 sampai dengan periode ke-48 dengan menggunakan parameter yang didapatkan dengan cara trial and error. Dengan menggunakan $\alpha=0,1$; maka pemulusan data periode ke-13 berdasarkan persamaan berikut:

$$
\begin{aligned}
& S_{13}=0,1 \frac{X_{t}}{S N_{t-1}}+(1-0,1)\left(S_{t-1}+T_{t-1}\right) \\
& S_{13}=0,1 \frac{3012}{1,017383}+(1-0,1)(2870,589+3,351111) \\
& S_{13}=2882,674
\end{aligned}
$$

Dengan menggunakan $\beta=0,1$; dilakukan pemulusan trend periode ke-13 dengan persamaan sebagai berikut: 
$T_{13}=0,1\left(S_{t}-S_{t-1}\right)+(1-0,1) T_{t-1}$

$T_{13}=0,1(2882,674-2870,589)+(1-0,1)$

$T_{13}=4,224436$

Dengan menggunakan $\gamma=0,1$; dilakukan pemulusan musiman untuk periode ke-13 dengan persamaan sebagai berikut:

$$
\begin{aligned}
& S N_{13}=0,1\left(\frac{X_{13}}{S_{13}}\right)+(1-0,1) S N_{13-12} \\
& S N_{13}=0,1\left(\frac{3012,75}{2882,674}\right)+(1-0,1) 1,017383 \\
& S N_{13}=1,020157
\end{aligned}
$$

Dengan cara yang sama, akan diperoleh pemulusan data, trend, dan musiman untuk periode ke 13 sampai dengan periode ke 48.

\subsubsection{Perhitungan Peramalan}

Setelah dilakukan pemulusan data, maka selanjutnya akan dilakukan peramalan untuk periode ke-37 sampai dengan periode ke- 48 dengan menggunakan $\alpha=0,1 ; \beta=0,1 ; \gamma=0,1$. Adapun hasil ramalan untuk periode ke-37 sampai dengan periode ke- 48 adalah sebagai berikut:

$$
\begin{aligned}
F_{36+1} & =\left(S_{36}+T_{36} m\right) S N_{36-12+1} \\
F_{36+1} & =(2912,641+1,811762.1) 1,01601 \\
F_{36+1} & =2961,113 \\
F_{36+2} & =\left(S_{36}+T_{36} m\right) S N_{36-12+2} \\
F_{36+2} & =(2912,641+1,811762.2) 1,023904 \\
F_{36+2} & =2985,974
\end{aligned}
$$

Lakukan hal yang sama untuk peramalan periode ke-37 sampai periode ke-48. Adapun hasil perhitungan pemulusan data, trend, musiman, dan peramalan pada tabel 3 .

Tabel 3 Nilai Pemulusan dan Peramalan dengan Menggunakan $\alpha=0,1 ; \beta=0,1 ; \gamma=0,1$ untuk Periode Ke-37 sampai dengan Periode Ke-48.

\begin{tabular}{cccccc}
\hline Periode & $\begin{array}{c}\text { Penggunaan } \\
\text { air }\end{array}$ & $\begin{array}{c}\text { Pemulusan } \\
\text { data }(\mathbf{S t})\end{array}$ & $\begin{array}{c}\text { Pemulusan trend } \\
(\mathbf{T t})\end{array}$ & $\begin{array}{c}\text { Pemulusan } \\
\text { Musiman }(\mathbf{S N t})\end{array}$ & $\begin{array}{c}\text { Ramalan Ft+m; } \\
\mathbf{t}=\mathbf{4 8} ; \mathbf{m}=\mathbf{1 2}\end{array}$ \\
\hline 37 & 2883,17 & 2906,781 & 1,044611 & 1,013597 & 2961,113 \\
38 & 2893,9 & 2899,677 & 0,22975 & 1,021314 & 2985,974 \\
39 & 2799,64 & 2882,696 & $-1,49135$ & 1,020822 & 2994,931 \\
40 & 2872,1 & 2867,158 & $-2,89607$ & 1,043311 & 3059,842 \\
41 & 2802,87 & 2844,558 & $-4,86637$ & 1,044303 & 3070,279 \\
42 & 2826,26 & 2831,512 & $-5,68434$ & 1,022125 & 2995,982 \\
43 & 2830,96 & 2825,722 & $-5,69496$ & 1,002159 & 2931,738 \\
44 & 2811,14 & 2841,83 & $-3,5146$ & 0,931696 & 2708,498 \\
45 & 2778,44 & 2835,19 & $-3,82722$ & 0,988824 & 2899,091 \\
46 & 2509,07 & 2810,971 & $-5,86632$ & 0,94871 & 2798,711 \\
47 & 2527,81 & 2792,009 & $-7,17594$ & 0,941288 & 2773,095 \\
\hline
\end{tabular}




\begin{tabular}{cccccc}
\hline Periode & $\begin{array}{c}\text { Penggunaan } \\
\text { air }\end{array}$ & $\begin{array}{c}\text { Pemulusan } \\
\text { data }(\mathbf{S t})\end{array}$ & $\begin{array}{c}\text { Pemulusan trend } \\
(\mathbf{T t})\end{array}$ & $\begin{array}{c}\text { Pemulusan } \\
\text { Musiman }(\mathbf{S N t})\end{array}$ & $\begin{array}{c}\text { Ramalan Ft+m; } \\
\mathbf{t}=\mathbf{4 8} ; \mathbf{m}=\mathbf{1 2}\end{array}$ \\
\hline 48 & 2857,15 & 2796,412 & $-6,01806$ & 0,988684 & 2890,406 \\
\hline
\end{tabular}

\subsubsection{Penentuan MAPE dan RMSE}

Setelah dilakukan pemulusan dan peramalan datanya, maka langkah selanjutnya adalah menentukan MAPE dan RMSE . Berikut Perhitungan mencari MAPE dan RMSE untuk peramalan periode ke-37 sampai dengan periode ke48.

Tabel 4 Perhitungan Mencari MAPE dan RMSE Untuk Ramalan Periode Ke-37 Sampai dengan Periode Ke-48

\begin{tabular}{ccccc|c|c}
\hline \multirow{2}{*}{ Periode } & Test Set & Ramalan & \multicolumn{2}{c}{$X t-F t\left|X_{t}-F_{t}\right|$} & $\left|\frac{X_{t}-F_{t}}{X_{t}}\right|$ & $\left(X_{t}-F_{t}\right)^{2}$ \\
\hline 37 & 2883,17 & 2961,11 & $-77,94$ & 77,94 & 0,02 & 6075,157 \\
38 & 2893,9 & 2985,97 & $-92,07$ & 92,07 & 0,03 & 8477,675 \\
39 & 2799,64 & 2994,93 & $-195,29$ & 195,3 & 0,07 & 38138,47 \\
40 & 2872,1 & 3059,84 & $-187,74$ & 187,7 & 0,065 & 35247,24 \\
41 & 2802,87 & 3070,27 & $-267,4$ & 267,4 & 0,095 & 71507,67 \\
42 & 2826,26 & 2995,98 & $-169,72$ & 169,7 & 0,06 & 28805,65 \\
43 & 2830,96 & 2931,74 & $-100,79$ & 100,8 & 0,04 & 10156,11 \\
44 & 2811,14 & 2708,49 & 102,64 & 102,6 & 0,04 & 10535,47 \\
45 & 2778,44 & 2899,09 & $-120,65$ & 120,7 & 0,04 & 14556,59 \\
46 & 2509,07 & 2798,71 & $-289,64$ & 289,6 & 0,12 & 83891,73 \\
47 & 2527,81 & 2773,09 & $-244,29$ & 244,3 & 0,1 & 59675,27 \\
48 & 2857,15 & 2890,4 & $-33,26$ & 33,26 & 0,01 & 1105,95 \\
\hline
\end{tabular}

Perhitungan MAPE dan RMSE dilakukan dengan membandingkan hasil peramalan untuk periode ke-37 sampai dengan periode ke-48 dari initialization set dengan test set. Berikut dilakukan perhitungan MAPE dan RMSE :

$$
\begin{aligned}
& \text { MAPE }=\frac{\sum_{t=1}^{n}\left|\frac{X_{t}-F_{t}}{X_{t}}\right|}{n} x 100 \% \\
& M A P E=\frac{\sum_{t=1}^{n}|0,688682|}{12} x 100 \% \\
& M A P E=5,73902 \\
& R M S E=\sqrt{\frac{\sum\left(X_{t}-F_{t}\right)^{2}}{n}} \\
& R M S E=\sqrt{\frac{368173}{12}} \\
& R M S E=175,1602
\end{aligned}
$$

Berdasarkan perhitungan diatas maka didapatkan hasil RMSE dan MAPE terhadap test set masing-masing sebesar 175,1602 dan 5,73902\%. Sehingga berdasarkan Tabel 2.1 Kriteria Nilai MAPE, hasil ini dapat dikatakan sangat baik karena MAPE kurang dari $10 \%$.

Langkah selanjutnya adalah melakukan perubahan terhadap parameter dengan mengkombinasikan nilai $\alpha, \beta, \gamma$ untuk mengetahui pengaruh jika nilai parameter itu diubah. Kombinasi nilai $\alpha, \beta, \gamma$ juga dilakukan untuk melihat model terbaik dari nilai MAPE dan RMSE terkecil . Batasan untuk setiap nilai adalah satu angka di belakang koma. 
Tabel 5 Kombinasi Nilai Parameter $\alpha, \beta, \gamma$ Untuk MAPE dan RMSE Terkecil.

\begin{tabular}{lllll}
\hline \multicolumn{2}{l}{ Parameter } & & MAPE & RMSE \\
\hline$\beta=0,1$ & $\gamma=0,1$ & $\alpha=0,1$ & 5,73902 & 175,1602 \\
& & $\alpha=0,3$ & 7,128599 & 213,9161 \\
& & $\alpha=0,6$ & 6,756356 & 201,9317 \\
$\alpha=0,1$ & $\gamma=0,1$ & $\beta=0,9$ & 5,122523 & 156,9162 \\
& & $\beta=0,3$ & 5,841646 & 179,116 \\
$\alpha=0,1$ & $\beta=0,6$ & 9,902012 & 298,5789 \\
0,1 & $\beta=0,9$ & 14,32784 & 419,9417 \\
& & $\gamma=0,3$ & 5,12186 & 168,534 \\
& & $\gamma=0,6$ & 4,736718 & 168,175 \\
& & $\gamma=0,9$ & 4,684674 & 172,425 \\
\hline
\end{tabular}

$$
\begin{aligned}
\text { MAPE } & =\frac{\sum_{t=1}^{n}\left|\frac{X_{t}-F_{t}}{X_{t}}\right|}{n} \times 100 \% \\
M A P E & =\frac{\sum_{t=1}^{n}|0,568406|}{12} \times 100 \% \\
M A P E & =4,736718
\end{aligned}
$$

$$
\begin{aligned}
& \text { RMSE }=\sqrt{\frac{\sum\left(X_{t}-F_{t}\right)^{2}}{n}} \\
& R M S E=\sqrt{\frac{339395}{12}} \\
& \text { RMSE }=168,1753
\end{aligned}
$$

MAPE dan RMSE terkecil diperoleh ketika $\alpha=0,1 ; \beta=0,1 ; \gamma=0,6$. Batasan untuk setiap nilai adalah satu angka di belakang koma. dengan nilai MAPE sebesar 4,736718 dan nilai RMSE sebesar 168,17

Tabel 6 Perhitungan Pemulusan Data, Trend, Musiman, serta Peramalan untuk Periode Ke-37 hingga Periode Ke-48 dengan $\alpha=0,1 ; \beta=0,1 ; \gamma=0,6$

\begin{tabular}{ccccccr}
\hline Periode & $\begin{array}{c}\text { Penggunaan } \\
\text { air }\end{array}$ & $\begin{array}{c}\text { Pemulusan } \\
\text { data }\left(\mathbf{S}_{\mathbf{t}}\right)\end{array}$ & $\begin{array}{c}\text { Pemulusan } \\
\text { trend }\left(\mathbf{T}_{\mathbf{t}}\right)\end{array}$ & $\begin{array}{c}\text { Pemulusan } \\
\text { Musiman }\left(\mathbf{S N}_{\mathbf{t}}\right)\end{array}$ & $\begin{array}{c}\text { Ramalan } \mathbf{F}_{\mathbf{t}+\mathbf{m}} ; \\
\mathbf{t = 4 8} \mathbf{\text { m} = 1 2}\end{array}$ & \multicolumn{1}{c}{ Error } \\
\hline 37 & 2883,17 & 2908,621 & 1,338429 & 0,995 & 2916,547 & 33,377 \\
38 & 2893,9 & 2905,713 & 0,913783 & 1,001 & 2940,455 & 46,555 \\
39 & 2799,64 & 2894,81 & $-0,26796$ & 0,982 & 2926,993 & 127,352 \\
40 & 2872,1 & 2884,235 & $-1,29863$ & 1,009 & 3001,219 & 129,119 \\
41 & 2802,87 & 2861,425 & $-3,44973$ & 1,008 & 3066,381 & 263,51 \\
42 & 2826,26 & 2852,632 & $-3,9841$ & 0,998 & 2942,93 & 116,669 \\
43 & 2830,96 & 2847,212 & $-4,12773$ & 0,996 & 2918,556 & 87,595 \\
44 & 2811,14 & 2844,691 & $-3,967$ & 0,986 & 2874,556 & 63,415 \\
45 & 2778,44 & 2849,055 & $-3,13395$ & 0,965 & 2779,673 & 1,232 \\
46 & 2509,07 & 2819,611 & $-5,76487$ & 0,922 & 2843,412 & 334,341 \\
47 & 2527,81 & 2793,278 & $-7,82174$ & 0,931 & 2838,447 & 310,637 \\
\hline
\end{tabular}


Dengan menggunakan parameter dengan nilai $\alpha=0,1 ; \beta=0,1 ; \gamma=0,6$, didapatkan model persamaan pemulusannya sebagai berikut:

1) Pemulusan Data

$$
S_{t}=0,1 \frac{X_{t}}{S N_{t-1}}+(0,9)\left(S_{t-1}+T_{t-1}\right)
$$

2) Pemulusan trend

$$
T_{t}=0,1\left(S_{t}-S_{t-1}\right)+(0,9) T_{t-1}
$$

3) Pemulusan Musiman

$$
S N_{t}=0,6\left(\frac{X_{t}}{S_{t}}\right)+(0,4) S N_{t-L}
$$

4) Sehingga model untuk peramalan periode selanjutnya adalah:

$$
\begin{aligned}
& F_{t+m}=\left(S_{t}+T_{t} m\right) S N_{t-L+m} \\
& F_{t+m}=\left(0,1 \frac{X_{t}}{S N_{t-1}}+(0,9)\left(S_{t-1}+T_{t-1}\right)+0,1\left(S_{t}-S_{t-1}\right)+(0,9) T_{t-1} \cdot m\right) 0,6\left(\frac{X_{t}}{S_{t}}\right)+(0,4) S N_{t-L+m}
\end{aligned}
$$

Dengan menggunakan keempat persamaan tersebut, maka diperoleh peramalan jumlah penggunaan air bersih (table 7).

Tabel 7 Peramalan jumlah penggunaan air bersih 12 bulan (2019)

\begin{tabular}{ll}
\hline Bulan & $\mathbf{2 0 1 9}$ \\
\hline Januari & 2779,1 \\
Februari & 2788,94 \\
Maret & 2728,61 \\
April & 2797,48 \\
Mei & 2787,97 \\
Juni & 2752,66 \\
Juli & 2742,18 \\
Agustus & 2708,5 \\
September & 2644,55 \\
Oktober & 2521,5 \\
November & 2537,74 \\
Desember & 2732,55 \\
\hline
\end{tabular}

Selanjutnya dilakukan perbandingan penggunaan air bersih tahun sebelumnya yaitu tahun 2018 dan tahun 2019 untuk melihat penggunaan air di PDAM Kota Makassar cenderung naik atau menurun, sehingga jumlah air yang harus di produksi oleh PDAM Kota Makassar untuk 12 bulan kedepan dapat dipersiapkan agar tidak terjadi kekurangan atau kelebihan air yang diproduksi.

Pada Tabel 8 dapat dilihat bahwa jumlah penggunaan air bersih di tahun 2019 tidak jauh berbeda dengan penggunaan air pada tahun sebelumnya yaitu tahun 2018. Sehingga bentuk dari plot data pada Gambar 4.5 memperlihatkan model yang tidak jauh berbeda bahkan hampir sama antara tahun 2018 dan 2019. 


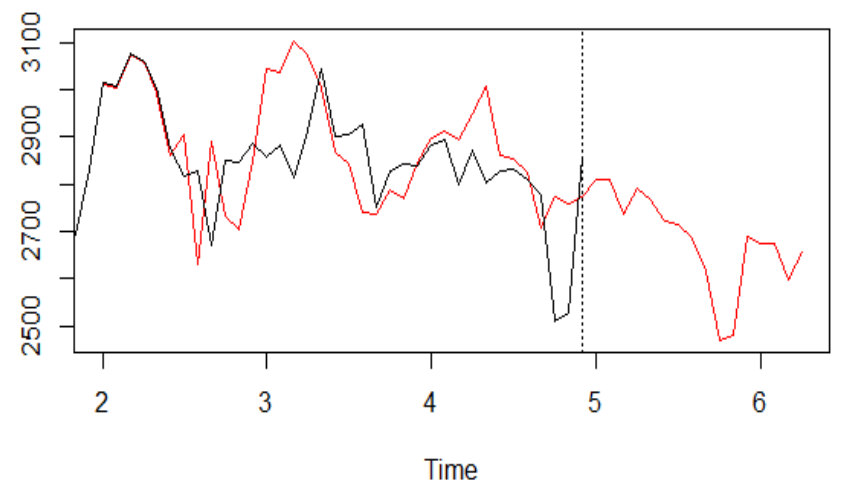

Gambar 3 Plot Pemulusan data dan Peramalan Jumlah Penggunaan Air Bersih

Berikut perbandingan jumlah penggunaan air bersih tahun 2018 dan tahun 2019.

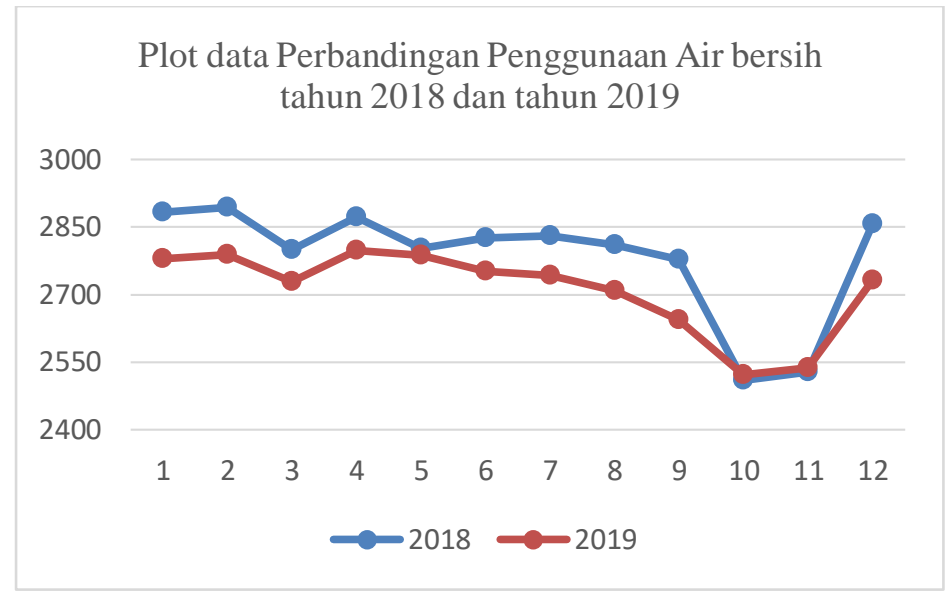

Gambar 4. Plot Data Perbandingan Penggunaan Air Bersih di PDAM Kota Makassar Tahun 2018 dan Tahun 2019

Tabel 8 Perbandingan Penggunaan Air Pada Periode Januari - Desember 2018 dan Januari - Desember 2019

\begin{tabular}{ccc}
\hline Bulan & $\mathbf{2 0 1 8}$ & $\mathbf{2 0 1 9}$ \\
\hline Januari & 2883,17 & 2779,1 \\
Februari & 2893,9 & 2788,94 \\
Maret & 2799,64 & 2728,61 \\
April & 2872,1 & 2797,48 \\
Mei & 2802,87 & 2787,97 \\
Juni & 2826,26 & 2752,66 \\
Juli & 2830,96 & 2742,18 \\
Agustus & 2811,14 & 2708,5 \\
September & 2778,44 & 2644,55 \\
Oktober & 2509,07 & 2521,5 \\
November & 2527,81 & 2537,74 \\
Desember & 2857,15 & 2732,55 \\
\hline
\end{tabular}




\subsection{Pembahasan}

Berdasarkan data yang diperoleh dari PDAM kota Makassar, menunjukkan bahwa keadaan jumlah penggunaan air bersih di kota Makassar pada bulan Januari 2015 - Desember 2018 mengandung faktor trend dan musiman sehingga dapat diramalkan menggunakan metode pemulusan eksponential smoothing yaitu Triple Exponential Smoothing atau Winter Exponential Smoothing.

Data jumlah penggunaaan air di PDAM Kota Makassar pada bulan Januari 2015-Desember 2018 memiliki pola historis yang tidak berfluktuasi (relatif stabil) sehingga nilai parameter pemulusan $\alpha$ mendekati 0 .

Berdasarkan Tabel 1. diketahui bahwa penggunaan air yang cukup tinggi berada di bulan Maret 2016 yaitu sebesar 3077,74 liter per detik dan terendah yaitu pada bulan oktober 2018 sebesar 2509,07 liter per detik. Model terbaik diperoleh dengan nilai parameter dengan nilai antara 0 sampai dengan 1. Ini merupakan iterasi yang dimulai dengan memilih antara 0,1 sampai 0,9 . Dari perhitungan semua $\alpha, \beta$, dan $\gamma$ yang telah dilakukan, diperoleh model terbaik yaitu dari kombinasi $\alpha=0,1 ; \beta=0,1 ; \gamma=0,6$ karena memiliki nilai RMSE dan MAPE terkecil. Berdasarkan hasil perhitungan kesalahan peramalan didapatkan hasil RMSE dan MAPE masing-masing sebesar 168,1753 dan $4,736718 \%$. Berdasarkan pengujian yang telah dilakukan, maka dapat dikatakan bahwa ketika nilai dari parameter $\alpha$ dan $\beta$ yang dibuat konstan dengan nilai 0,1 memiliki nilai MAPE yang lebih kecil dibandingkan ketika $\beta$ dan $\gamma$, ataupun $\alpha$ dan $\gamma$ yang dibuat konstan. Makridakis dkk., (1999) menyebutkan bahwa nilai $\alpha$ yang besar $(0,9)$ memberikan pemulusan yang sangat kecil dalam peramalan, sedangkan nilai $\alpha$ yang kecil $(0,1)$ memberikan pemulusan yang besar. Sehingga berdasarkan Tabel 2.1 Kriteria Nilai MAPE, hasil ini dapat dikatakan sangat baik karena MAPE kurang dari 10\%. Semakin kecil kesalahan peramalannya maka semakin baik pula peramalannya, hal ini sesuai dengan pendapat Gasperz(2005:80) yang menyatakan bahwa akurasi peramalan akan semakin tinggi jika nilai-nilai MAPE dan RMSE semakin kecil. Dari hasil perhitungan peramalan dengan menggunakan metode Triple Exponential Smoothing untuk 12 bulan ke depan tahun 2019 dengan $\alpha=0,1 ; \beta=0,1 ; \gamma=0,6$ menggunakan model peramalan :

$$
F_{t+m}=\left(0,1 \frac{X_{t}}{S N_{t-1}}+(0,9)\left(S_{t-1}+T_{t-1}\right)+0,1\left(S_{t}-S_{t-1}\right)+(0,9) T_{t-1} \cdot m\right) 0,6\left(\frac{X_{t}}{S_{t}}\right)+(0,4) S N_{t-L+m}
$$

yaitu Januari, Februari, Maret, April, Mei, Juni, Juli, Agustus, September, Oktober, November, Desember sebesar 2779,$10 ; 2788,94 ; 2728,61 ; 2797,48 ; 2787,97 ; 2752,66 ; 2742,18 ; 2708,50 ; 2644,55 ; 2521,50 ; 2537,74 ; 2732,55$.

Prediksi atau ramalan untuk bulan Januari 2019-Desember 2019 mengalami penurunan dari tahun sebelumnya namun tidak terlalu signifikan, menunjukkan hasil ramalan yang baik karena nilai yang dihasilkan mendekati atau cenderung sama dengan pola data di tahun sebelumnya yaitu Januari 2018-Desember 2018.

Peramalan terhadap produksi di perusahaan dimasa yang akan datang setidaknya memberikan gambaran terhadap perusahaan mengenai kondisi atau keadaan yang akan terjadi agar memberikan ruang terhadap pimpinan perusahaan untuk mengontrol dan mengantisipasi segala kemungkinan yang terjadi dimasa yang mendatang.

\section{Kesimpulan}

Berdasarkan hasil dan pembahasan, diperoleh kesimpulan:

1. Data jumlah penggunaan air di PDAM kota Makassar dari tahun 2015-2018 mengandung faktor trend dan musiman sehingga dapat diramalkan menggunakan metode pemulusan eksponential smoothing yaitu triple exponential smoothing dengan kombinasi parameter $\boldsymbol{\alpha}=\mathbf{0 , 1 ;} \boldsymbol{\beta}=\mathbf{0 , 1} ;$ dan $\gamma=0,6$ dengan MAPE dan RMSE terkecil masing-masing ssebesar 4,736718 dan 168,175

2. Model pemulusan dan peramalan yang diperoleh adalah sebagai berikut:

Pemulusan Data :

$$
S_{t}=0,1 \frac{X_{t}}{S N_{t-1}}+(0,9)\left(S_{t-1}+T_{t-1}\right)
$$


Pemulusan Trend

$$
T_{t}=0,1\left(S_{t}-S_{t-1}\right)+(0,9) T_{t-1}
$$

Pemulusan Musiman

$$
S N_{t}=0,6\left(\frac{X_{t}}{S_{t}}\right)+(0,4) S N_{t-L}
$$

Peramalan

$$
F_{t+m}=\left(0,1 \frac{X_{t}}{S N_{t-1}}+(0,9)\left(S_{t-1}+T_{t-1}\right)+0,1\left(S_{t}-S_{t-1}\right)+(0,9) T_{t-1} \cdot m\right) 0,6\left(\frac{X_{t}}{S_{t}}\right)+(0,4) S N_{t-L+m}
$$

3. Dengan menggunakan model peramalan

$$
F_{t+m}=\left(0,1 \frac{X_{t}}{S N_{t-1}}+(0,9)\left(S_{t-1}+T_{t-1}\right)+0,1\left(S_{t}-S_{t-1}\right)+(0,9) T_{t-1} \cdot m\right) 0,6\left(\frac{X_{t}}{S_{t}}\right)+(0,4) S N_{t-L+m}
$$

diperoleh hasil peramalan untuk bulan Januari 2019 - Desember 2019 secara berturut-turut sebesar 2779,10; 2788,$94 ; 2728,61 ; 2797,48 ; 2787,97 ; 2752,66 ; 2742,18 ; 2708,50 ; 2644,55 ; 2521,50 ; 2537,74 ; 2732,55$ dengan nilai MAPE sebesar 4,736718 dan nilai RMSE sebesar 168,1753

4. Banyaknya jumlah penggunaan air di PDAM Kota Makassar sangat dipengaruhi oleh pengaruh musiman namun kurang dipengaruhi oleh faktor trend sehingga nilai peramalan yang dihasilkan tidak jauh berbeda dengan nilai pada data sebelumnya.

\section{References}

Aswi \& Sukarna. (2006). Analisis Deret Waktu. Makkassar: Andira.

Bossarito, P. (2018). Jurnal Pengembangan Teknologi Informasi dan Ilmu Komputer. Prediksi Jumlah Kebutuhan Pemakaian Air Menggunakan Metode Exponential Smoothing (Studi kasus : PDAM Kota Malang), 4681.

Chang, Pei-Chann, Chen-Hao Liu, Chia-Hsuan Yeah,Shih-Hsin Cen (2007). The Development of a Weighted Evolving Fuzzy Neural Network for PCB Sales Forecasting, Elseiver, 32(Expert Systems with Applications), 86-96.

Fiati, R. (2010). Aplikasi Sistem Pendukung Keputusan Peramalan Penjualan Barang.

Ginanjar Susilo, Ibnu, Ika Yulia Iswiyanita, Elga Puri Megantari, Laila Ziadatu Mawaddah, Dena Aurum Salehah, Agustini Tripena Br.Sb., Agung Prabowo. (2016). Peramalan Volume Penggunaan Air Bersih Dengan Metode Winters Exponential Smoothing Untuk Menentukan Volume Air Bersih Yang Harus Diproduksi Oleh PDAM Tirta Satria. Purwokerto.

Kurniawati, E. (2009). Analisis Rasio Keuangan untuk menilai Kinerja Perusahaan Daerah Air Minum (Studi Kasus Pada PDAM di Kota Sorong). Analisis, 6(2), 112-122.

Makridakis dkk. (1999). Metode dan Aplikasi Peramalan (terjemahan). Jakarta: Binarupa Aksara.

Putri, T. (2012). Aplikasi Sistem Peramalan Penjualan Penjualan Barang Dengan Menggunakan Metode Pemulusan Exponential Tunggal (Studi Kasus PT. Sri Mekar Cahaya Persada Banjarmasin).

Spyros, Makridakis Steven,C. (n.d.). Wheelwright. Op Cit, 64.

Sugiyanto.S, R. K. (2016). Implementasi Metode Triple Exponential Smoothing dalam Peramalan Penjualan Pulsa Elektrik.

Suwandi Adi, A. K. (2015). Peramalan Data Time Series dengan Metode Penghalusan Eksponential Holt-Winter. Universitas Negeri Makassar.

Trihendradi, C. (2005). SPSS 13 : Analisis Data Statistik. Yogyakarta: Yogyakarta Andi.

Utami \& Atmojo, R. (2017). Perbandingan Metode Holt Exponential Smoothing dan Winter Exponential Smoothing untuk peramalan penjualan souvenir, 124 